\title{
Cold reactive antilymphocyte antibodies in neurological diseases
}

\author{
R O BERT P. LISAK, FELICULA MERCA DO, \\ A N D B U R T O N Z W E I M A N
}

From the Department of Neurology and Division of Allergy and Immunology, Department of Medicine, School of Medicine, University of Pennsylvania, Philadelphia, Pennsylvania, USA

SUMMARY Cold reactive $\left(15^{\circ} \mathrm{C}\right)$ antilymphocyte antibodies were detected in the sera of $33 \%$ of patients with multiple sclerosis, $50 \%$ with Guillain-Barré syndrome, $42 \%$ with myasthenia gravis, and $38 \%$ with polymyositis. We did not detect such antibodies against autologous cells in multiple sclerosis. In multiple sclerosis there was no correlation between the presence of antilymphocytic antibodies and disease activity or duration. In patients with multiple sclerosis, myasthenia gravis, and polymyositis there was no correlation between the presence of cold reactive antilymphocyte antibodies and abnormalities of $\mathrm{T}$ or $\mathrm{B}$ cell levels.

Cold reactive $\left(15^{\circ} \mathrm{C}\right)$ antilymphocyte antibodies are found in the serum of patients with various diseases including tumours, viral infections, and putative autoimmune diseases (Messner, 1975). Among patients with neurological diseases, such antibodies have been reported in the serum of patients with multiple sclerosis (Kuwert and Bertrams, 1972; Schocket et al., 1977; Schocket and Weiner, 1978), subacute sclerosing panencephalitis (Schocket et al., 1977), myasthenia gravis (Kreisler et al., 1971), and polymyositis (Terasaki et al., 1970).

The function or role of such antibodies is not known, but in systemic lupus erythematosus it has been suggested they might play a role in producing a state of lymphopenia or depressed immunity (Butler et al., 1972; Williams et al., 1973). We, therefore, have examined the serum of patients with various neurological diseases and attempted to see if a correlation existed between the presence of such antibodies and the relative and absolute levels of circulating thymic dependent lymphocytes ( $T$ cells) or thymic independent lymphocytes (B cells).

\section{Patients and methods}

Serum was obtained from all subjects and stored

Address for reprint requests: Dr Robert P. Lisak, Department of Neurology, Hospital of the University of Pennsylvania, 3400 Spruce Street, Philadelphia, Pa 19104, USA.

Accepted 17 May 1979 at $-70^{\circ} \mathrm{C}$ until used. Replicate aliquots were placed in wells of histoplates (Cooke Laboratory Products, Alexandria Va). The replicate plates were stored at $-70^{\circ} \mathrm{C}$ until used for the assay. Serum was obtained from 67 patients with multiple sclerosis, 14 with acute Guillain-Barré syndrome, 15 with amyotrophic lateral sclerosis, 69 with myasthenia gravis, 21 with polymyositis, nine with dermatomyositis, and 21 with other neurological diseases. The latter group included three patients with subacute sclerosing panencephalitis, five with occlusive cerebrovascular disease, five with acute disseminated encephalomyelitis, two with systemic lupus erythematosus with central nervous system involvement, one with aseptic meningitis, three with Duchenne type muscular dystrophy, one with spinocerebellar degeneration, and one with polyarteritis nodosa with mononeuritis multiplex. Serum was also obtained from 46 normal control subjects matched for age and sex. The clinical disease activity was categorised for the multiple sclerosis and myasthenia gravis patients as described previously (Lisak and Zweiman, 1977; Lisak et al.. 1978).

ASSAY OF T AND B CELL LEVELS

Levels of circulating $T$ cells and $B$ cells were determined on the day that the serum was obtained from many of the patients and control subjects as noted in Results. $T$ cells were assayed using our modification (Lisak et al., 1975) of the ability of human $\mathrm{T}$ lymphocytes to bind to nonsensitised 
sheep red blood cells (SRBC; E rosettes) and B cells by the ability to bind to SRBC coated with 19S anti-SRBC and mouse complement (EAC rosettes). Since measurement of antilymphocyte antibodies is essentially qualitative, we compared the presence of such antibodies with the presence or absence of a decrease or increase of $\mathrm{T}$ or $\mathrm{B}$ cells in comparison with the normal range for our laboratory $(\% \mathrm{E}$ rosettes $62 \pm 2$; total $\mathrm{E}$ rosettes $1419 \pm 76 ; \%$ EAC rosettes $20 \pm 1$; total EAC rosettes $468 \pm 37$ ) (Lisak et al., 1978).

\section{ASSAY FOR COLD REACTING ANTILYMPHOCYTE}

ANTIBODIES

Cold reactive antilymphocyte antibodies were assayed employing a two-stage microdroplet assay (Zimjewski, 1979) but with all incubations performed at $15^{\circ} \mathrm{C}$. All plates contained wells with (1) positive control sera from three patients with active nephritis of systemic lupus erythematosus, and (2) negative controls-(a) pooled normal AB negative serum and (b) human serum albumin (HSA) in phosphate buffered saline (PBS) at a concentration of $5 \mathrm{~g} / \mathrm{dl}$.

Lymphocytes were obtained by Ficoll-Hypaque gradient centrifugation. Serum from every subject was tested with cells from 10-18 allogenic normal cell donors. In addition, sera from eight patients with multiple sclerosis and from seven normal subjects were also tested with autologous cells.

A serum sample which produced cell death, as measured by incorporation of eosin, in $\geqslant 20 \%$ of the lymphocytes from $\geqslant 20 \%$ of the normal donors tested was considered to contain antilymphocyte antibodies (Messner, 1975).

\section{Results}

Cold reactive antilymphocyte antibodies were found in the sera of 13 of our normal subjects. There was a significantly increased prevalence of cold reactive antibodies in the serum of patients with several neurological diseases (Table) including multiple sclerosis (33\%), Guillain-Barré syndrome $(50 \%)$, myasthenia gravis $(42 \%)$, and polymyositis $(38 \%)$. Twenty-seven per cent of sera obtained from patients with amyotrophic lateral sclerosis and $33 \%$ of samples from patients with dermatomyositis were also positive but the increase in these two groups was not significant $(\mathrm{P}<0.3$ and 0.2 respectively). Sera from six of 21 patients with other neurological diseases had cold reactive antilymphocyte antibodies. This included two patients with subacute sclerosing panencephalitis, one with occlusive cerebral vascular disease complicated by sepsis, one with spino-
Table Cold reacting antilymphocyte antibodies in patients with neurological diseases and normal subjects

\begin{tabular}{lccl}
\hline Diagnosis & $\begin{array}{l}\text { Number } \\
\text { positivel } \\
\text { Number } \\
\text { tested }\end{array}$ & $(\%)$ & $\begin{array}{l}\mathrm{P} * \text { value } \\
\text { versus } \\
\text { normal } \\
\text { subjects }\end{array}$ \\
\hline Normal & $6 / 46$ & $(13)$ & \\
Multiple sclerosis & $22 / 47$ & $(33)$ & $\mathrm{P}<0.05$ \\
Guillain-Barré syndrome & $7 / 14$ & $(50)$ & $\mathrm{P}<0.01$ \\
Amyotrophic lateral sclerosis & $4 / 15$ & $(27)$ & $\mathrm{P}<0.3$ \\
Myasthenia gravis & $29 / 69$ & $(42)$ & $\mathrm{P}<0.01$ \\
Polymyositis & $8 / 21$ & $(38)$ & $\mathrm{P}<0.05$ \\
Dermatomyositis & $3 / 9$ & $(33)$ & $\mathrm{P}<0.2$ \\
Other neurological diseases $\dagger$ & $6 / 21$ & $(29)$ & $\mathrm{P}<0.2$ \\
\hline
\end{tabular}

*Determined by $\chi^{2}$ analysis of $2 \times 2$ contingency table.

$\uparrow$ The positives in this group included two patients with subacute sclerosing panencephalitis; one with spinocerebellar degeneration; one with stroke and sepsis, and two with systemic lupus erythematosus with central nervous system involvement.

cerebellar degeneration and axonal peripheral neuropathy, and two with systemic lupus erythematosus and active central nervous system disease.

The incidence of cold reactive antilymphocyte antibodies in the serum of patients with multiple sclerosis with different patterns of disease activity was compared. No statistically significant difference was found (multiple sclerosis in exacerbation $=28 \%$, with a rapidly progressive course $=45 \%$, in remission $=32 \%)$. Duration of disease $(\leqslant 2$ years $=35 \% ;>2$ years $=30 \%$ ) also seemed not to be a discriminating factor in the incidence of antilymphocyte antibodies.

There was no difference between the incidence of antilymphocyte antibodies in patients with severe generalised $(45 \%)$ and mild generalised $(50 \%)$ myasthenia gravis; the serum of one of the four patients with ocular myasthenia contained such antibodies. The prevalence of antibodies in patients with past or present thymoma $(27 \%)$ and those without thymoma (based on chest radiography, tomography, and/or surgical pathological examination) $(44 \%)$ did not differ significantly from one another.

Determinations of $\mathrm{E}$ and EAC rosettes as measures of $T$ and $B$ cells were carried out in sufficient numbers of patients with multiple sclerosis, myasthenia gravis, and polymyositis, and in normal subjects to allow for meaningful comparisons. In none of these groups was there any significant correlation between increase or decrease in percentage or absolute levels of $T$ or $B$ cells and the presence of cold reactive antilymphocyte antibodies.

In eight multiple sclerosis patients and seven normal subjects, sera from multiple (5-20/subject) bleedings were tested with autologous lymphocytes. No evidence of toxicity was observed. 


\section{Discussion}

Cold reactive antilymphocyte antibodies have been reported in neurological diseases. Among these are multiple sclerosis (Kuwert and Bertrams, 1972; Schocket et al., 1977; Schocket and Weiner, 1978), subacute sclerosing panencephalitis (Schocket et al., 1977), myasthenia gravis (Kreisler et al., 1971) and polymyositis (Terasaki et al., 1970). We have confirmed the presence of such antibodies in these disorders. In addition we have found that the sera of $50 \%$ of patients with acute GuillainBarré syndrome contain such antibodies. The prevalence of serum antilymphocyte antibodies was increased in patients with amyotrophic lateral sclerosis and dermatomyositis but these increases were not statistically significant. However, the number of patients with dermatomyositis studied was quite small $(\mathrm{N}=9)$.

Kuwert and Bertrams (1972) were able to show a higher incidence of antilymphocyte antibodies in multiple sclerosis sera reacting with cells from other patients with multiple sclerosis than with cells from normal donors. However, we were unable to demonstrate cold reactive antilymphocyte antibodies directed against autologous lymphocytes in the serum of eight patients with multiple sclerosis.

The biological significance of cold reacting antilymphocyte antibodies is not clear (Messner, 1975; Kunkle et al., 1975). The reasons for these antibodies being demonstrated optimally at $15^{\circ} \mathrm{C}$ are not known. Changes in the metabolism of the lymphocytes, conformational changes in the antigen(s) in the lymphocyte membrane, and changes in the antibody immunoglobulin have all been suggested as possible factors.

The role and function, if any, of these antibodies is likewise not known. The appearance of these antibodies in some diseases in which a degree of depressed cellular immunity occurs (systemic lupus erythematosus, Hodgkin's disease) or might occur (subacute sclerosing panencephalitis, multiple sclerosis, myasthenia gravis) has led to the suggestion of an immunoregulatory role. In systemic lupus erythematosus, a correlation between disease activity, evidence of immunosuppression, and presence of antilymphocyte antibodies is compatible with an immunoregulatory role for these antibodies (Butler et al., 1972; Williams et al., 1973; Messner, 1975). In this study, however, we found no correlation between the presence of cold reacting antilymphocyte antibodies and the relative or absolute levels of circulating blood T and B lymphocytes, as assayed by $\mathrm{E}$ and $\mathrm{EAC}$ rosetting techniques, in multiple sclerosis, myasthenia gravis, and polymyositis.

Several groups have reported that the serum of some patients with multiple sclerosis has the capacity to inhibit the in vitro proliferation of lymphocytes in culture (Knowles et al., 1968; Sternjholm et al., 1970). The nature of this substance(s) is not known (White et al., 1975). The conditions for optimal lymphocyte culture and demonstration of cold reactive antilymphocyte an iibodies are dissimilar. However, warm reactive antilymphocyte antibodies which are capable of inhibition of mixed leucocyte reactions in vitro have been detected in the sera of some patients with systemic lupus erythematosus (Wernet and Kunkle, 1973) as well as in pregnant women and transplant patients (Revillard et al., 1972). These antibodies seem to be in the IgG class while the cold reacting antilymphocyte antibodies are predominantly if not entirely in the IgM class.

The presence of cold reactive antilymphocyte antibodies is thought by some to be evidence for viral or other infections (Messner, 1975). In systemic lupus erythematosus (DeHoratius and Messner, 1974; Messner, 1975) and multiple sclerosis (Schocket and Weiner, 1978) the increased prevalence of such antibodies in genetically related and unrelated household members has been interpreted as indicating a response to an environmental agent.

Another possible explanation for the occurrence of antilymphocyte antibodies is that they are a normal response, perhaps with some immunoregulatory function, that occurs as a result of a strong antigenic stimulation. Thirty per cent of normal individuals develop such antibodies transiently after immunisation (Kreisler et al., 1970), and patients with bacterial infections (Kreisler et al., 1971) also have these antibodies. The very much higher incidence of antibodies and their possible cytotoxic activity in certain diseases might then represent persistence of antigenic stimulation or inflammatory reaction.

This study was supported by grants USPHS NS1 1037 and RO1 NS14327.

\section{References}

Butler, W. T., Sharp, J. T., Rossen, R. D., Lidsky, K., Mittall, K., and Gard, K. (1972). Relationship of the clinical course of systemic lupus erythematosus to the presence of circulating lymphocytotoxins antibodies. Arthritis Rheumatology, 15, 231237.

DeHoratius, R. J., and Messner, R. P. (1974). Lymphocytotoxins in relatives of patients with 
systemic lupus erythematosus. Clinical Research, 22, $180 \mathrm{~A}$.

Knowles, M., Hughes, D., Caspary,, E., and Field, E. J. (1968). Lymphocyte transformation in multiple sclerosis. Inhibition of unstimulated thymidine uptake by a serum factor. Lancet, 2, 207-1209.

Kreisler, M. J., Hirata, A. A., and Terasaki, P. I. (1970). Cytotoxins in disease III antibodies against lymphocytes produced by vaccination. Transplantation, 10, 411-415.

Kreisler, M. J., Naito, S., and Terasaki, P. I. (1971). Cytotoxins in disease V. Various diseases. Transplant Proceedings, 3, 112-114.

Kunkle, H. G., Winfield, J. B., Winchester, R. J., and Wernet, P. (1975). Antibodies to lymphocytes in human sera. In Lymphocytes and their Interactions, pp. 183-201. Edited by R. C. Williams Jr. Raven Press: New York.

Kuwert, E., and Bertrams, J. (1972). Leukocyte iso and autoantibodies in multiple sclerosis (MS) with special regard to complement dependent cold reacting autolymphocytotoxins (CoCoCy). European Neurology, 7, 65-73.

Lisak, R. P., and Zweiman, B. (1977). In vitro cellmediated immunity of cerebrospinal fluid lymphocytes to myelin basic protein in primary demyelinating diseases. New England Journal of Medicine, 297, 850-853.

Lisak, R. P., Zweiman, B., and Phillips, S. M. (1978). Thymic and peripheral blood $\mathrm{T}$ and B-cell levels in myasthenia gravis. Neurology (Minneapolis), 28, 1298-1301.

Lisak, R. P., Levinson, A. I., Zweiman, B., and Abdou, N. I. (1975). T and B-lymphocytes in multiple sclerosis. Clinical and Experimental Immunology, 22, 30-34.

Messner, R. P. (1975). Naturally occurring antilymphocyte antibodies. In Lymphocytes and their Interactions, pp. 169-181. Edited by R. C. Williams Jr. Raven Press: New York.
Revillard, J. P., Robert, M. M., Beutal, H., Latour, M., Bonneau, M., Brochier, J., and Frager, J. (1972). Inhibition of the mixed leukocyte reaction by antibodies. Transplant Proceedings, 44, 173-176.

Schocket, A., Weiner, H. L., Walker, J., McIntosh, K., and Kohler, P. F. (1977). Lymphocytotoxic antibodies in patients with multiple sclerosis. Clinical Immunology and Immunopathology, 7, 1523.

Schocket, A., and Weiner, H. L. (1978). Lymphocytotoxic antibodies in family members of patients with multiple sclerosis. Lancet, 1, 571-573.

Sternjholm, R. L., Wheelock, E. F., and van den Noort, S. (1970). A lymphocytotoxic factor in multiple sclerosis serum. Journal of the Reticuloendothelial Society, 8, 334-341.

Terasaki, P. I., Vilma, D., Mottironi, M. D., and Barnett, E. V. (1970). Cytotoxins in disease: autocytotoxins in lupus. New England Journal of Medicine, 283, 724-728.

Wernet, P., and Kunkle, H. G. (1973). Demonstration of specific $T$ lymphocyte membrane antigens associated with antibodies inhibiting the mixed leukocyte culture in man. Transplant Proceedings, 5, 1875-1881.

White, G., Armantrout, S., and van den Noort, S. (1975). Partial purification and characterisation of a lymphotoxic factor from multiple sclerosis serum. Neurology (Minneapolis), 25, 37-42.

Williams, R. C., Lies, R. B., and Messner, R. P. (1973). Inhibition of mixed leukocyte culture response by serum and $\gamma$-globulin fractions from certain patients with connective tissue disorders. Arthritis Rheumatology, 16, 597-605.

Zimjewski, C. M. (1979). 23-Lymphocyte microcytotoxicity: two-stage method. Appendix in Immunohematology, third edition, pp. 324-325. Appleton Century Crofts: New York. 